\title{
Delayed periprosthetic collection after cervical disc arthroplasty
}

\author{
Lauren Harris, MChem, MBBS, MRCS, ${ }^{1}$ Edward Dyson, MBBS, MRCS, ${ }^{1}$ \\ Matthew Elliot, MA(Cantab), MB BChir, MRCS, ${ }^{1}$ David Peterson, FRCS, FRCS(SN), ${ }^{1}$ \\ Christian Ulbricht, MD, FRCS(SN), ${ }^{1}$ and Adrian Casey, MBBS, FRCS(SN) ${ }^{2}$
}

\begin{abstract}
1Department of Neurosurgery, Imperial College Healthcare NHS Trust, Charing Cross Hospital, London, United Kingdom; and 2Department of Neurosurgery, The National Hospital for Neurology and Neurosurgery, Queen Square, London, United Kingdom
\end{abstract}

\begin{abstract}
Cervical disc arthroplasty is a treatment option for symptomatic cervical disc disease. There is a paucity of literature on long-term safety outcomes, durability, and device-related failure rates. The M6-C artificial cervical disc is a device with titanium alloy endplates and a complex polymeric centerpiece. To date, trials have exhibited acceptable safety profiles.

This case series describes the presentation, management, and pathological findings of a delayed prevertebral periprosthetic mass anterior to the M6-C disc. Four patients at 3 different institutions underwent cervical disc replacement with the M6-C disc. Two to seven years postoperatively, they presented with dysphagia secondary to a compressive mass anterior to the disc. Case notes were reviewed to collect data on symptoms, management, and outcomes. The patients were systemically well and presented with progressive dysphagia. They had imaging findings of a mass anterior to the disc. They underwent a decompressive procedure, with 2 patients undergoing device removal and fusion. In 2 cases, a soft-tissue mass was seen intraoperatively, with frank pus. In 3 cases, Propionibacterium acnes was identified and antibiotic treatment given. Histopathology demonstrated mixed inflammatory infiltrates with foreign body-type granulomas. Postoperatively, the dysphagia resolved.
\end{abstract}

The development of delayed dysphagia in a patient with an M6-C disc should prompt investigation to identify a mass lesion. To the authors' knowledge, this is the first report of delayed infection, or suspected delayed-type hypersensitivity reaction, following M6-C disc implantation. It is important for this to be added to the device safety concerns. Further prospective studies are needed to establish the incidence and the long-term safety and failure rates of the M6-C disc.

https://thejns.org/doi/abs/10.3171/2019.9.SPINE19900

KEYWORDS arthroplasty; dysphagia; Propionibacterium acnes; infection; hypersensitivity; safety; cervical

A RTHROPLASTY and anterior cervical discectomy and fusion are successful means of relieving cervical radiculopathy and arresting the progression of cervical myelopathy. ${ }^{22}$ Cervical disc arthroplasty emerged in the 1960 s as an alternative treatment option to fusion. ${ }^{22}$

Meta-analyses have consistently shown modern arthroplasty devices to be comparable or superior to fusion overall, with improved neurological outcome, patient satisfaction, dysphagia, range of movement, and reoperation rates $(6 \%$ in arthroplasty vs $12 \%$ in discectomy and fusion). ${ }^{21,39,41-45}$ The literature commonly reports outcomes at 1-5 years. , $^{8}$ However, there is limited information concerning longer-term safety outcomes, durability, and device-related failure rates of arthroplasty. ${ }^{27,40}$

Cervical arthroplasty has a number of distinct compli- cations. Radiculopathy from compression by inflammatory hyaline cartilaginous material has been observed. ${ }^{7}$ Bone loss, delayed heterotopic ossification in the vicinity of the arthroplasty, progressive osteolysis of the vertebral body by the superior keel of the alloy endplate, and a posterior avulsion fracture of the adjacent vertebral body have been reported. ${ }^{16,20,35}$

The M6-C artificial disc (2006, Spinal Kinetics) has been designed to replicate the anatomical, physiological, and biomechanical characteristics of a native disc. It incorporates a compressible nucleus pulposus with a woven fiber annulus fibrosis. ${ }^{30}$ It is a single-piece device with titanium alloy endplates and a complex centerpiece composed of a polycarbonate urethane polymeric material, surrounded by a polyethylene woven fiber construct. ${ }^{31} \mathrm{~A}$ 
polymer sheath surrounds the centerpiece, preventing tissue ingrowth and debris entry. ${ }^{44}$ It incorporates all 6 degrees of freedom in its kinematics profile. ${ }^{30}$

Feasibility trials have exhibited acceptable safety profiles, with the absence of serious device-related adverse events, surgical reintervention, or radiographic evidence of device migration or expulsion following arthroplasty. ${ }^{30}$

This case series is the first report of delayed failure of the M6-C artificial disc due to a mass developing anterior to the disc, causing dysphagia and compressive symptoms. To what extent this mass is caused by a soft-tissue reaction to the implant material or by a bacterial infection is to be determined and is discussed below.

\section{Case Reports}

Case 1

A 63-year-old man underwent a C4-5 anterior cervical discectomy and disc replacement with the M6-C artificial disc in April 2013 at institution 1. The patient had an uncomplicated recovery postoperatively. He remained systemically well but in 2017 became increasingly dysphagic. In December 2017, a CT scan of the neck with contrast revealed a soft-tissue mass anterior to the $\mathrm{C} 4-5$ replacement disc with a cervical fluid collection (Fig. 1). He had no Modic changes on MRI. Inflammatory markers were unremarkable.

The patient underwent removal of the disc and drainage of the suspected abscess. Intraoperatively, frank pus drained from around the right side of the disc. The M6-C disc was intact and not loose. No iliac bone graft or plate was used to maximize infection clearance. The patient was kept in a Miami J collar for 6 weeks. Flexion and extension radiographs obtained 6 weeks postoperatively confirmed bony destruction of the endplates, minor loss of intervertebral height, with well-preserved alignment and no significant slip (Fig. 2). His dysphagia resolved postoperatively, and he remains symptom free.

Histopathological examination revealed mixed inflammatory infiltrates with abundant neutrophils and fibrin deposits. Numerous macrophages with scanty giant cells, but no granuloma formation, were seen. The disc-space cultures grew Propionibacterium acnes on 16S ribosomal RNA (rRNA) molecular sequencing. The patient's white blood cell count and C-reactive protein level remained normal. He was treated with 6 weeks of intravenous antibiotics as directed by the infectious disease team: 5 days of teicoplanin followed by amoxicillin and rifampicin.

\section{Case 2}

A 68-year-old man underwent C4-5 and C5-6 anterior cervical discectomy and disc replacement with the M6-C artificial disc at C5-6 (and a cage at C4-5) in 2010 at institution 1, following spondylotic radiculopathy. The patient was followed up every 6 months, as he complained of ongoing paresthesia in the C5 and C6 distribution. He was otherwise clinically well with normal inflammatory markers. In January 2017 he presented with an itchy throat, which his general practitioner initially thought was due to hay fever. His dysphagia rapidly progressed, prompting further investigation initially by the otolaryngology team,

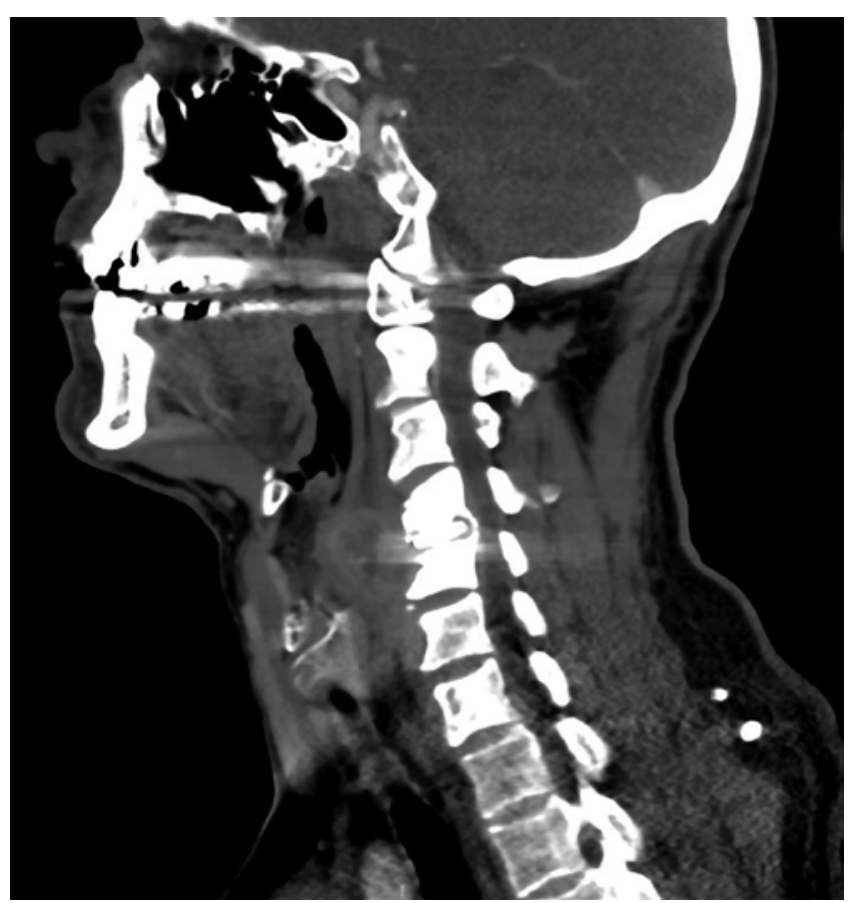

FIG. 1. Case 1. Contrast-enhanced sagittal CT scan of the neck, showing mass effect anterior to the C4-5 level.

who did not identify the implant complication, and then by the neurosurgery team.

An MRI study obtained in February 2017 revealed a prevertebral fluid collection spanning $\mathrm{C} 4-5$, contiguous with the C5-6 disc space. On reflection, this was evident on an MRI scan in 2012 but had significantly increased in size. With this time course in mind, it was thought likely to be a chronic inflammatory reaction to the disc prosthesis. CT scanning of the cervical spine performed in April 2017 revealed progressive osteolysis of the vertebral body margins adjacent to the disc prosthesis and widening of the prevertebral soft tissues secondary to a complex encapsulated collection (Fig. 3). He had Modic type 3 changes on preoperative imaging.

In May 2017, the patient underwent implant removal and fusion of C4-6 with an iliac crest autologous bone graft and anterior plate fixation. The soft-tissue mass was identified and partially removed. The patient's inflammatory markers remained normal, and he was treated with 2 days of cefuroxime prophylactically. His symptoms resolved, and postoperative CT scanning findings were satisfactory, showing a stable fixation (Fig. 4).

Histopathological examination demonstrated moderate chronic active inflammation, with foreign body-type granulomas and fibrosis within the connective tissue. Cultures were negative, including for fungal infections and acid-fast bacillus. No 16S rRNA molecular sequencing was performed.

\section{Case 3}

A 51-year-old man underwent a C5-6 and C6-7 anterior cervical discectomy and disc replacement with the M6-C artificial disc in 2012, following left-sided radiculopathy. This was performed at institution 2 . 


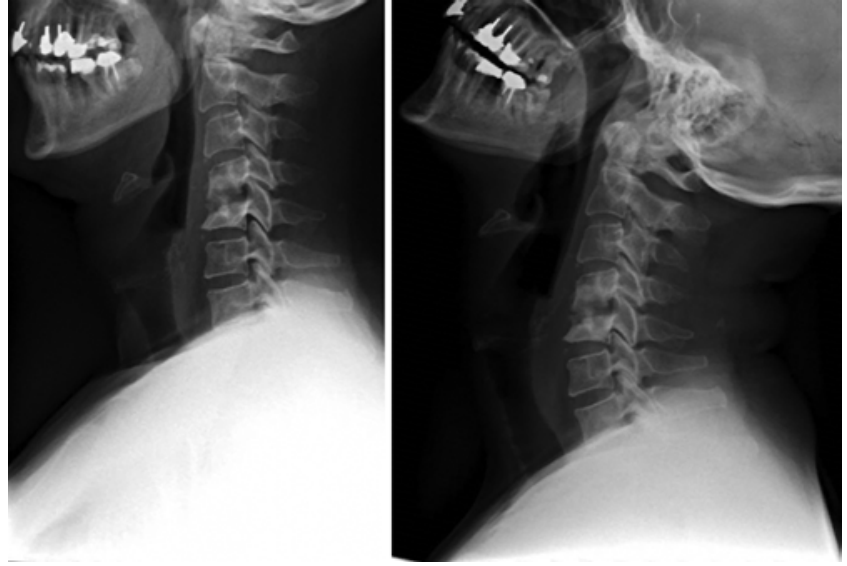

FIG. 2. Case 1. Stable flexion (left) and extension (right) radiographs obtained 6 weeks postoperatively, showing improved swelling.

In 2017, the patient presented with a 4-month history of dysphagia to institution 1 . This was initially treated as gastroesophageal reflux disease with a proton pump inhibitor. Symptoms progressively worsened with associated coughing, neck discomfort, and developing respiratory compromise. On examination, he had pain on neck flexion and right-sided lateral flexion. He was systemically well, with normal inflammatory markers. An ultrasound scan and MRI showed a large retropharyngeal collection, anterior to the disc replacement, compressing the esophagus and other neck structures (Fig. 5).

The patient was admitted for an anterior cervical wound exploration in December 2017. On opening of the wound, frank pus was seen, and the mass was communicating with the metallic implant. The abscess was drained, and the prosthesis was left in situ. Postoperatively, the patient's dysphagia resolved and imaging demonstrated a residual abnormality (Fig. 5). A decision was made that the implant would be removed should the symptoms or mass recur.

Histopathology showed areas of granulation tissue, with foamy histiocytes, hemosiderin, and flakes of foreign body material engulfed by multinucleated giant cells, with adjacent scar tissue. The pus at operation was sterile, but $P$. acnes was isolated on $16 \mathrm{~S}$ rRNA molecular sequencing. The implant was left in situ, which created difficulties with infection eradication. The patient was treated rigorously with amoxicillin intravenously and linezolid for 1 week, then intravenous ceftriaxone for a further 6 weeks (with oral linezolid for 4 weeks), followed by doxycycline and rifampicin orally for 12 months, as per the infectious disease team.

At 20 months' follow-up after washout, there has been no clinical or radiological recurrence. Imaging findings remain stable with no evidence of fusion or bone loss.

\section{Case 4}

A 48-year-old man underwent a C5-6 and C6-7 anterior cervical discectomy and disc replacement with the M6-C artificial disc in June 2014. This operation was done at institution 3. In August 2016, the patient developed a persistent sore throat, mild dysphagia, and neck swelling. By December 2016 he had a sinus formation with pus discharge from the surgical scar. He presented to institution 2. His inflammatory markers were unremarkable. MRI showed a superficial collection with enhancing surgical tracks extending deep to the vertebral bodies between C5 and C7 and osteomyelitis with extensive inflammatory changes. Posterior to the vertebral bodies there was extradural, subligamentous high signal. CT demonstrated lucency at the artificial disc endplates. A fistulous connection between the pharynx and cervical spine was ruled out by video fluoroscopy.

Following multidisciplinary team input, the patient underwent a wound exploration and drainage. The decision to leave the disc in situ was based on an increased risk of surgical complications due to the infection and the unknown significance of creating a new nidus with further metalwork.

Intraoperative tissue culture and 16S rRNA molecular sequencing isolated $P$.acnes. The patient was treated with combination antibiotics for an extended course of 1 year. $\mathrm{He}$ received intravenous benzylpenicillin, clindamycin, and ceftriaxone with oral ciprofloxacin, rationalized to intravenous ceftriaxone with oral clindamycin, followed by oral clindamycin and rifampicin, then clindamycin mono-
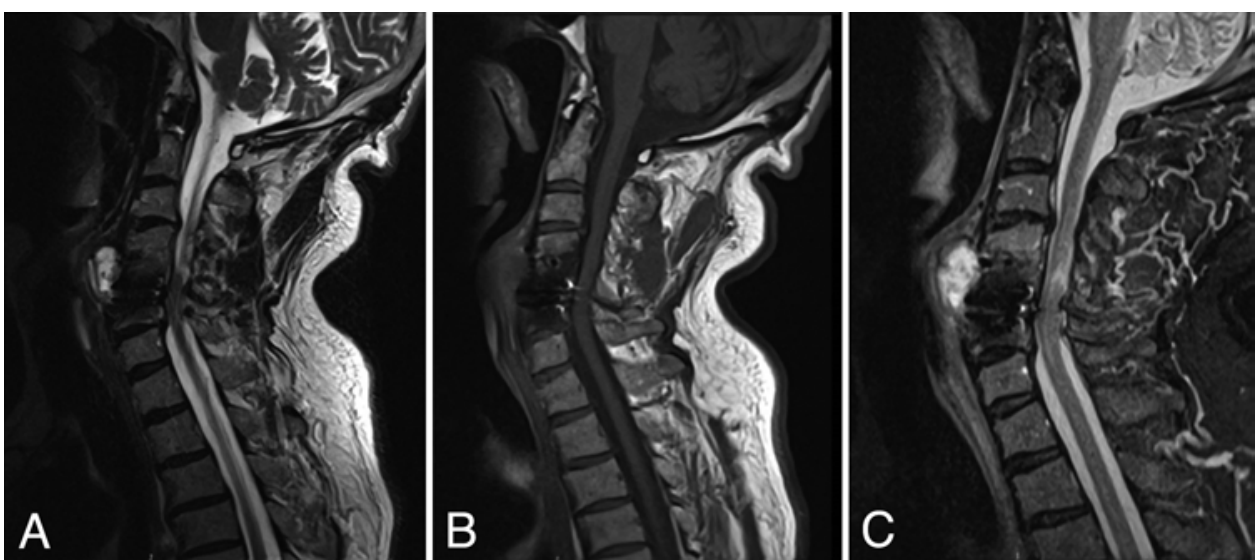

FIG. 3. Case 2. Sagittal T2-weighted (A), T1-weighted (B), and STIR MR (C) images, showing prevertebral fluid collection. 


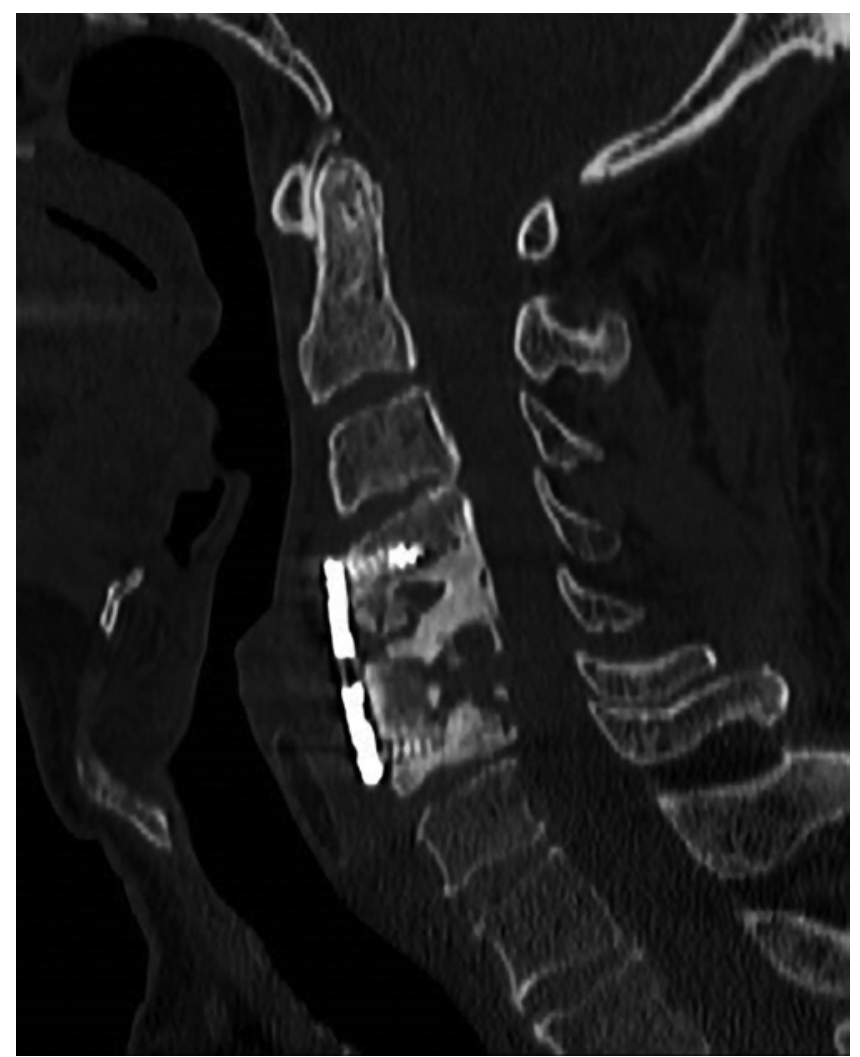

FIG. 4. Case 2. Postoperative CT scan showing plate fixation.

therapy for the remaining 6 months. After experiencing continuous discharge from the wound, he additionally underwent hyperbaric oxygen therapy for 40 sessions from April 2017.

Follow-up imaging in December 2016 showed improved superficial collection, but no change in the deep component, with extensive prevertebral inflammation (Fig. 6). At the 32-month follow-up, he has no ongoing symptoms, and MRI findings were stable with suspected fusion across the device.

\section{Results}

To our knowledge, this case series is the first report of delayed failure of the M6-C artificial disc due to a mass developing anterior to the disc, presenting as dysphagia. A summary of the 4 cases can be seen in Table 1 .

A total of 145 M6-C discs have been implanted at the 3 institutions since 2010, with no other revisions or complications noted. Standard skin preparation techniques and antibiotic surgical cover were utilized. The 3 consultant neurosurgeons have cumulatively had more than 50 years' experience and have performed approximately 3000 anterior cervical spine operations. In addition to the cases above, they have seen 2 other delayed infections (one in an anterior vertebral cage, which was removed). Treatment decisions were made after multidisciplinary team discussion with patient involvement (notably, 2 patients were surgeons themselves). The decision to leave the implants in situ for cases 3 and 4 was due to the increased risk of

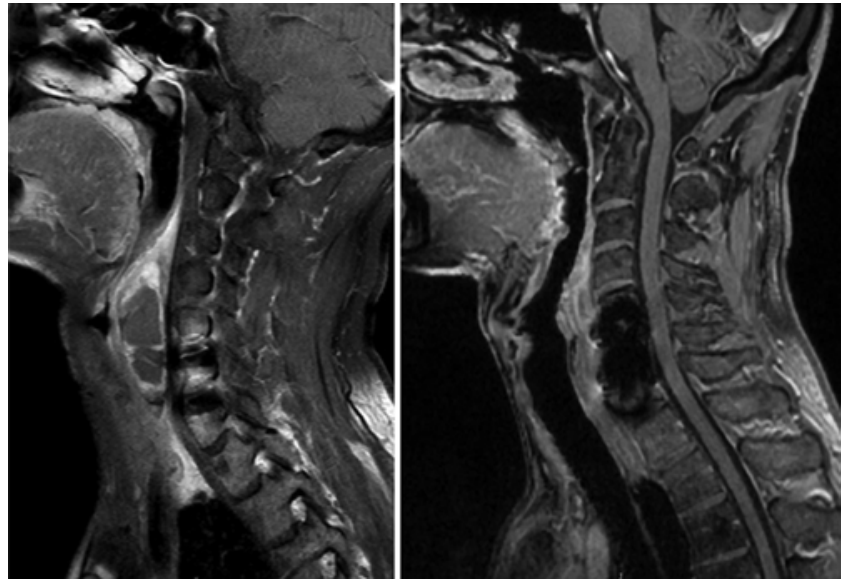

FIG. 5. Case 3. Preoperative (left) and postoperative (right) sagittal T1weighted contrast-enhanced MR images demonstrating retropharyngeal fluid collection.

surgical complications. At 20 and 32 months postoperatively, respectively, the patients have no symptoms and stable imaging findings.

\section{Discussion}

In a retrospective study of the M6-C artificial disc, 24 of 33 patients experienced dysphagia immediately postoperatively, and 3 had persistent, sustainable complaints. ${ }^{37}$ Late complications included collapse of the underlying endplate $(n=2)$, causing subsidence of the prosthesis and requiring reoperation and fusion, and aseptic loosening of the prosthesis $(n=1) .{ }^{37}$ There was no expulsion or mechanical failure. ${ }^{37} \mathrm{~A}$ further case identified posterior core herniation of the M6-C disc 8 years after implantation. ${ }^{6}$ A report exists of a cystic mass anterior to a Bryan disc (which has a polyurethane center with titanium endplates, similar to the M6-C disc), presenting 8 years after surgery. ${ }^{11}$

In late operative site problems such as our own, there is a debate about whether these issues are caused by softtissue reaction to the implant material or due to bacterial infection: $;^{13,32}$ they are discussed in turn below.

\section{Soft-Tissue Reaction}

Adjacent tissue reaction to metal debris is well documented, and has been given a variety of names: aseptic lymphocytic vasculitis-associated lesions, pseudotumor, necrosis, adverse reaction to metal debris, and adverse local tissue response. ${ }^{32}$ Histological examination of failed metal-on-metal hip replacements has demonstrated metallosis with lymphocytic and plasma-cell infiltration, with the formation of soft-tissue pseudotumors. ${ }^{26}$

Reasons for these occurrences remain speculative. Depending on the biomaterial implant properties, there can be release and deposition of corrosion and wear debris, including metal ions. ${ }^{12,19}$ Particulate debris or ionic degradation products can form local metal-protein complexes and subsequently elicit an acquired immune response as seen in a type IV, delayed hypersensitivity reaction. ${ }^{19} \mathrm{~A}$ toxic effect of metal ions, independent of the immune re- 

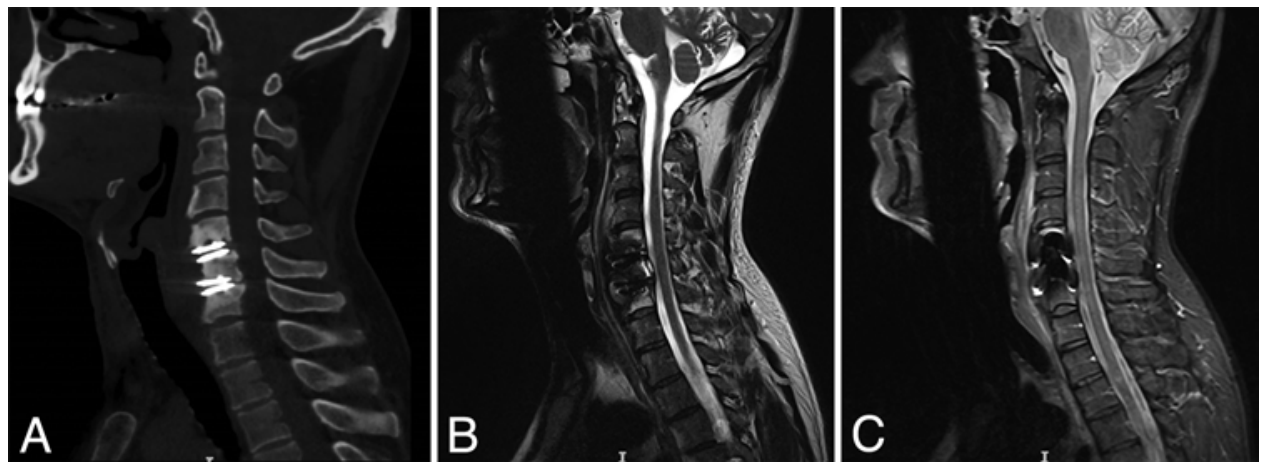

FIG. 6. Case 4. Postoperative sagittal CT (A), T2-weighted MR (B), and STIR (C) images demonstrating stable but extensive prevertebral inflammation.

sponse, can lead to cell necrosis. ${ }^{15}$ Polymeric debris appears to be the most common wear by-product in cervical disc implants with metal on polymeric articulations, with an accompanying inflammatory reaction in surrounding host tissue. ${ }^{38}$ Patient genetics regulate the response to the debris. ${ }^{19}$

There have been a number of cases of abnormal inflammatory reactions to metal ions with epidural spinal cord compression following spinal arthroplasty.,12,13 One series looks at 4 cases of lymphocytic reactions to the implants, requiring disc removal and fusion. ${ }^{12}$ All patients developed axial pain or radicular symptoms $10-18$ months postoperatively and had a compressive mass lesion on imaging. ${ }^{12}$ Intraoperatively, a thick, yellow, avascular soft-tissue mass was found epidurally in the lumbar cases, and a graytinged soft-tissue response was seen around the cervical case, suggestive of metallosis. ${ }^{12}$ Pathology revealed fat necrosis, fibrosis, and chronic inflammation dominated by lymphocytes, with macrophages and eosinophils. Spectroscopy findings of particles rich in chromium, oxygen, cobalt, and phosphorus demonstrated that the mass was related to the metallic implant rather than infection. In one case, like our own, the disc-space cultures grew P. acnes. ${ }^{12}$

With spinal implants, there is continued load sharing between the implants and the fusion mass, which may lead to continued stress and subsequently fretting corrosion. ${ }^{32}$ Titanium particulate debris has been shown to elicit a cytokine-mediated response favoring proinflammatory mediators and increased expression of intracellular tumor necrosis factor- $\alpha . .^{10,32}$ The M6-C disc has 2 titanium endplates separated by a polymeric core. In our case series, intraoperatively, the implants were solidly fixed despite erosions around them and the soft-tissue response was evident. The mass made dissection more difficult than a typical revision procedure.

\section{Bacterial Infection}

While acute infection following an anterior cervical approach is known to occur in $0 \%-1 \%$ of cases, delayed infection is very rare. ${ }^{29}$ Bacterial infection may be from hematogenous seeding of bacteria or intraoperative seeding followed by subclinical quiescent periods. ${ }^{13}$ Low-virulence skin flora are the main organisms of delayed infection, with P. acnes, Staphylococcus aureus, and Staphylococcus epidermis being the most cited. ${ }^{13,17,28,34}$
P. acnes is a slow-growing, gram-positive, pleomorphic, diphtheroid-like anaerobic bacillus. It specifically resides in pilosebaceous follicles of the skin but can also be found in the conjunctiva, oral cavity, and intestinal tract. ${ }^{33}$ Due to the higher prevalence within hair follicles and pores, infection is more common in men. ${ }^{33} P$. acnes can play 2 roles: it has proinflammatory properties and can behave as a pyogenic bacterium in acute inflammatory reactions. ${ }^{4}$ Infections are characteristically delayed and hard to diagnose..$^{14}$ The indolent nature of the infection is illustrated by the prolonged duration of symptoms prior to presentation, lack of fever, usually normal inflammatory markers, and the significant time lapse from previous surgery to presentation (as seen in our series). ${ }^{24} P$. acnes has a high affinity for deep skin structures. ${ }^{13}$

$P$. acnes infection is a well-documented late complication of instrumented spine surgery, often in the form of osteomyelitis or on the prosthesis. ${ }^{4,14,17}$ The reported incidence rates of delayed infections are $0.3 \%-9.7 \%$, increasing up to $54 \%$ in instrumented spinal cases. ${ }^{4,9,17,34}$ The incidence is higher with improved culture techniques, as $P$. acnes requires extended periods of incubation. ${ }^{4}$ In our study, 16S rRNA molecular sequencing was used to isolate the organism.

$P$. acnes can frequently invade the circulatory system during tooth brushing but does not pose an immediate risk due to the aerobic environment of the blood. ${ }^{1,5,23}$ Avascular, anaerobic discs, with a low oxygen tension and low $\mathrm{pH}$, provide an ideal environment for anaerobic bacteria to multiply. ${ }^{1}$ With Modic changes in the lumbar spine, organisms can gain access to the disc as a result of neovascularization associated with disc degeneration or herniation..$^{1,2}$ Microorganisms are present in extruded nuclear tissue in $46 \%-71 \%$ of patients with lumbar disc herniations, with P. acnes being the most common. ${ }^{1}$ It is possible that the low-virulence P. acnes enters the M6-C disc (for example, the pseudoannulus) and gives rise to a slow-developing infection.

Low inoculation during surgery may enable it to reside intracellularly and dormant. ${ }^{13}$ It is unclear why the inoculation changes into a clinical infection years later, but mechanical irritation, bursa formation, and metal fretting corrosion have been postulated as cofactors.,13

$P$. acnes forms a biofilm on the prosthesis, necessitating a long course of antibiotics. ${ }^{3}$ Most infections after spinal 


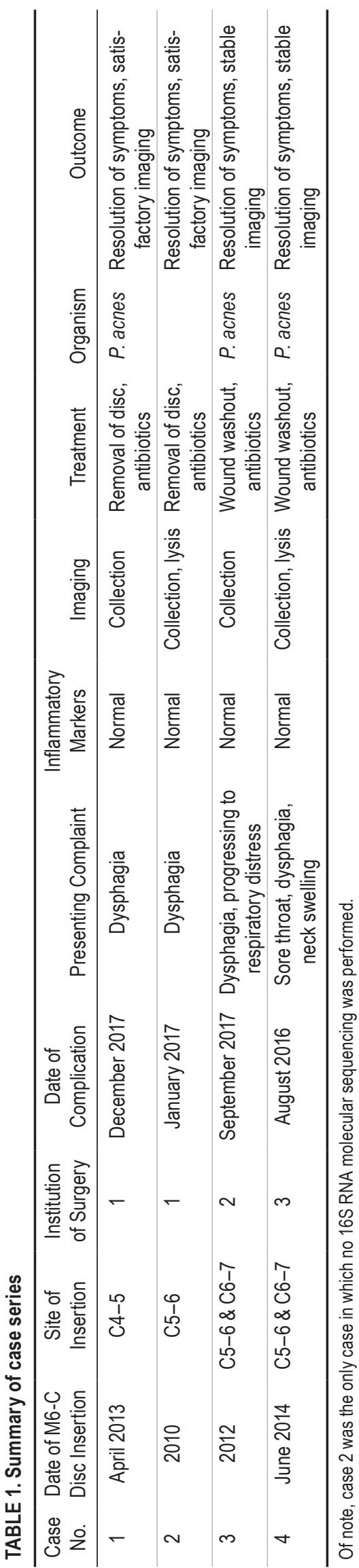

instrumentation are treated with implant removal plus antibiotic therapy. ${ }^{4}$ In cases in which removal is not possible, treatment with antibiotics alone has been successful. ${ }^{4}$ The risk of relapse is increased with the use of monotherapy or treatment for less than 3 months. ${ }^{3,4}$ Interestingly, studies have demonstrated that $P$. acnes forms a denser biofilm on titanium than on other metals. ${ }^{36}$ This governed our extensive antibiotic regimen in cases 3 and 4, where the titanium-based M6-C disc was left in situ.

To our knowledge, this is the first report of suspected delayed-type hypersensitivity reaction, or delayed infection, following M6-C disc insertion. These complications occurred in our patients following implantation at 3 different institutions. It is important for these events to be added to the safety concerns for the device. The development of delayed symptoms in a patient with an M6-C disc, with no clinical evidence of infection, should prompt further investigations to detect a mass.

The cases have been reported to the Healthcare Products Regulatory Agency. We contacted Spinal Kinetics, which confirmed (in April 2019) that there have been "a very low number of reports of latent and occult $P$. acnes (and limited other species)." These events (including our cases) were investigated by the company, which found no correlation to specific manufacturing or sterilization lots of product.

We are in the process of a single-center retrospective cohort study of all patients who underwent anterior cervical disc replacement with the M6-C disc via a screening questionnaire, asking about neck pain, dysphagia, and radiculopathy. Those who are deemed high risk will be called in for radiography imaging, a clinic review, and further investigation.

There are several limitations to our study. First, it is a case series. Second, it is difficult to determine if our report demonstrates septic or aseptic failure of the M6-C disc or whether these cases are an indolent infection following spinal implantation. This difference has important implications clinically and financially, with potential prolonged antibiotic treatment, increased length of stay, and further surgeries. There is no practical guide to differentiate between metal hypersensitivity and infection. Third, comparison of the $P$. acnes strain was inconclusive. Culture of intraoperative specimens may present false positives or negatives due to cross-contamination or previous antimicrobial therapy ${ }^{15}$ Further investigations can help with this distinction, including patch testing to show the presence of an immunological reaction induced by the antigen, measurement of ion levels within the mass lesion, or quantification of neutrophil polymorph infiltrate as shown in hip revision arthroplasty. ${ }^{25}$

\section{Conclusions}

A prospective, observational study is needed to establish the incidence of delayed mass formation following anterior cervical disc replacement and variation between different manufacturers and models. Further investigation is needed to look at the long-term safety outcomes, durability, and rates of failure of the M6-C disc specifically. 


\section{Acknowledgments}

We thank the patients who consented to the publication of this case series.

\section{References}

1. Albert HB, Lambert P, Rollason J, Sorensen JS, Worthington $\mathrm{T}$, Pedersen MB, et al: Does nuclear tissue infected with bacteria following disc herniations lead to Modic changes in the adjacent vertebrae? Eur Spine J 22:690-696, 2013

2. Albert HB, Sorensen JS, Christensen BS, Manniche C: Antibiotic treatment in patients with chronic low back pain and vertebral bone edema (Modic type 1 changes): a double-blind randomized clinical controlled trial of efficacy. Eur Spine J 22:697-707, 2013

3. Bayston R, Nuradeen B, Ashraf W, Freeman BJC: Antibiotics for the eradication of Propionibacterium acnes biofilms in surgical infection. J Antimicrob Chemother 60:1298-1301, 2007

4. Bémer P, Corvec S, Tariel S, Asseray N, Boutoille D, Langlois C, et al: Significance of Propionibacterium acnespositive samples in spinal instrumentation. Spine (Phila Pa 1976) 33:E971-E976, 2008

5. Bhanji S, Williams B, Sheller B, Elwood T, Mancl L: Transient bacteremia induced by toothbrushing a comparison of the Sonicare toothbrush with a conventional toothbrush. Pediatr Dent 24:295-299, 2002

6. Brenke C, Schmieder K, Barth M: Core herniation after implantation of a cervical artificial disc: case report. Eur Spine J 24 (Suppl 4):S536-S539, 2015

7. Cavanaugh DA, Nunley PD, Kerr EJ III, Werner DJ, Jawahar A: Delayed hyper-reactivity to metal ions after cervical disc arthroplasty: a case report and literature review. Spine (Phila Pa 1976) 34:E262-E265, 2009

8. Chen C, Zhang X, Ma X: Durability of cervical disc arthroplasties and its influence factors: a systematic review and a network meta-analysis. Medicine (Baltimore) 96:e5947, 2017

9. Chen Y, Wang X, Zhang X, Ren H, Huang B, Chen J, et al: Low virulence bacterial infections in cervical intervertebral discs: a prospective case series. Eur Spine J 27:2496-2505, 2018

10. Cunningham BW, Orbegoso CM, Dmitriev AE, Hallab NJ, Sefter JC, McAfee PC: The effect of titanium particulate on development and maintenance of a posterolateral spinal arthrodesis: an in vivo rabbit model. Spine (Phila Pa 1976) 27:1971-1981, 2002

11. Fan $\mathrm{H}, \mathrm{Wu} \mathrm{S}, \mathrm{Wu} \mathrm{Z}$, Wang Z, Guo Z: Implant failure of Bryan cervical disc due to broken polyurethane sheath: a case report. Spine (Phila Pa 1976) 37:E814-E816, 2012

12. Guyer RD, Shellock J, MacLennan B, Hanscom D, Knight $\mathrm{RQ}, \mathrm{McCombe}$ P, et al: Early failure of metal-on-metal artificial disc prostheses associated with lymphocytic reaction: diagnosis and treatment experience in four cases. Spine (Phila Pa 1976) 36:E492-E497, 2011

13. Hahn F, Zbinden R, Min K: Late implant infections caused by Propionibacterium acnes in scoliosis surgery. Eur Spine J 14:783-788, 2005

14. Haidar R, Najjar M, Der Boghossian A, Tabbarah Z: Propionibacterium acnes causing delayed postoperative spine infection: review. Scand J Infect Dis 42:405-411, 2010

15. Hallab NJ, Anderson S, Caicedo M, Brasher A, Mikecz K, Jacobs JJ: Effects of soluble metals on human peri-implant cells. J Biomed Mater Res A 74:124-140, 2005

16. Heo DH, Lee DC, Oh JY, Park CK: Bone loss of vertebral bodies at the operative segment after cervical arthroplasty: a potential complication? Neurosurg Focus 42(2):E7, 2017

17. Hu X, Lieberman IH: Revision spine surgery in patients without clinical signs of infection: How often are there occult infections in removed hardware? Eur Spine J 27:2491-2495, 2018

18. $\mathrm{Hu}$ Y, Lv G, Ren S, Johansen D: Mid- to long-term outcomes of cervical disc arthroplasty versus anterior cervical discectomy and fusion for treatment of symptomatic cervical disc disease: a systematic review and meta-analysis of eight prospective randomized controlled trials. PLoS One 11:e0149312, 2016

19. Jacobs JJ, Campbell PA, T Konttinen Y: How has the biologic reaction to wear particles changed with newer bearing surfaces? J Am Acad Orthop Surg 16 (Suppl 1):S49-S55, 2008

20. Kong L, Ma Q, Meng F, Cao J, Yu K, Shen Y: The prevalence of heterotopic ossification among patients after cervical artificial disc replacement: a systematic review and metaanalysis. Medicine (Baltimore) 96:e7163, 2017

21. Latka D, Kozlowska K, Miekisiak G, Latka K, Chowaniec J, Olbrycht T, et al: Safety and efficacy of cervical disc arthroplasty in preventing the adjacent segment disease: a meta-analysis of mid- to long-term outcomes in prospective, randomized, controlled multicenter studies. Ther Clin Risk Manag 15:531-539, 2019

22. Leven D, Meaike J, Radcliff K, Qureshi S: Cervical disc replacement surgery: indications, technique, and technical pearls. Curr Rev Musculoskelet Med 10:160-169, 2017

23. Lockhart PB, Brennan MT, Sasser HC, Fox PC, Paster BJ, Bahrani-Mougeot FK: Bacteremia associated with toothbrushing and dental extraction. Circulation 117:3118-3125, 2008

24. Nisbet M, Briggs S, Ellis-Pegler R, Thomas M, Holland D: Propionibacterium acnes: an under-appreciated cause of postneurosurgical infection. J Antimicrob Chemother 60:10971103, 2007

25. Pandey R, Drakoulakis E, Athanasou NA: An assessment of the histological criteria used to diagnose infection in hip revision arthroplasty tissues. J Clin Pathol 52:118-123, 1999

26. Pandit H, Glyn-Jones S, McLardy-Smith P, Gundle R, Whitwell D, Gibbons CLM, et al: Pseudotumours associated with metal-on-metal hip resurfacings. J Bone Joint Surg Br 90:847-851, 2008

27. Park CK, Ryu KS: Are controversial issues in cervical total disc replacement resolved or unresolved?: A review of literature and recent updates. Asian Spine J 12:178-192, 2018

28. Portillo ME, Corvec S, Borens O, Trampuz A: Propionibacterium acnes: an underestimated pathogen in implant-associated infections. BioMed Res Int 2013:804391, 2013

29. Quaile A: Infections associated with spinal implants. Int Orthop 36:451-456, 2012

30. Reyes-Sanchez A, Miramontes V, Olivarez LMR, Aquirre AA, Quiroz AO, Zarate-Kalfopulos B: Initial clinical experience with a next-generation artificial disc for the treatment of symptomatic degenerative cervical radiculopathy. SAS J 4:9-15, 2010

31. Sears WR, McCombe PF, Sasso RC: Kinematics of cervical and lumbar total disc replacement. Semin Spine Surg 18:117-129, 2006

32. Shang X, Wang L, Kou D, Jia X, Yang X, Zhang M, et al: Metal hypersensitivity in patient with posterior lumbar spine fusion: a case report and its literature review. BMC Musculoskelet Disord 15:314, 2014

33. Shields MV, Abdullah L, Namdari S: The challenge of Propionibacterium acnes and revision shoulder arthroplasty: a review of current diagnostic options. J Shoulder Elbow Surg 25:1034-1040, 2016

34. Shifflett GD, Bjerke-Kroll BT, Nwachukwu BU, Kueper J, Burket J, Sama AA, et al: Microbiologic profile of infections in presumed aseptic revision spine surgery. Eur Spine J 25:3902-3907, 2016

35. Shim CS, Shin HD, Lee SH: Posterior avulsion fracture at ad- 
jacent vertebral body during cervical disc replacement with ProDisc-C: a case report. J Spinal Disord Tech 20:468-472, 2007

36. Shiono Y, Ishii K, Nagai S, Kakinuma H, Sasaki A, Funao $\mathrm{H}$, et al: Delayed Propionibacterium acnes surgical site infections occur only in the presence of an implant. Sci Rep 6:32758, 2016

37. Thomas S, Willems K, Van den Daelen L, Linden P, Ciocci MC, Bocher P: The M6-C cervical disk prosthesis: first clinical experience in 33 patients. Clin Spine Surg 29:E182E187, 2016

38. Veruva SY, Steinbeck MJ, Toth J, Alexander DD, Kurtz SM: Which design and biomaterial factors affect clinical wear performance of total disc replacements? A systematic review. Clin Orthop Relat Res 472:3759-3769, 2014

39. Xie L, Liu M, Ding F, Li P, Ma D: Cervical disc arthroplasty (CDA) versus anterior cervical discectomy and fusion (ACDF) in symptomatic cervical degenerative disc diseases (CDDDs): an updated meta-analysis of prospective randomized controlled trials (RCTs). Springerplus 5:1188, 2016

40. Xu JC, Goel C, Shriver MF, Tanenbaum JE, Steinmetz MP, Benzel EC, et al: Adverse events following cervical disc arthroplasty: a systematic review. Global Spine J 8:178-189, 2018

41. Xu S, Liang Y, Zhu Z, Qian Y, Liu H: Adjacent segment degeneration or disease after cervical total disc replacement: a meta-analysis of randomized controlled trials. J Orthop Surg Res 13:244, 2018

42. Yao Q, Liang F, Xia Y, Jia C: A meta-analysis comparing total disc arthroplasty with anterior cervical discectomy and fusion for the treatment of cervical degenerative diseases. Arch Orthop Trauma Surg 136:297-304, 2016

43. Zhong ZM, Li M, Han ZM, Zeng JH, Zhu SY, Wu Q, et al: Does cervical disc arthroplasty have lower incidence of dysphagia than anterior cervical discectomy and fusion? A metaanalysis. Clin Neurol Neurosurg 146:45-51, 2016
44. Zhong ZM, Zhu SY, Zhuang JS, Wu Q, Chen JT: Reoperation after cervical disc arthroplasty versus anterior cervical discectomy and fusion: a meta-analysis. Clin Orthop Relat Res 474:1307-1316, 2016

45. Zou S, Gao J, Xu B, Lu X, Han Y, Meng H: Anterior cervical discectomy and fusion (ACDF) versus cervical disc arthroplasty (CDA) for two contiguous levels cervical disc degenerative disease: a meta-analysis of randomized controlled trials. Eur Spine J 26:985-997, 2017

\section{Disclosures}

The authors report no conflict of interest concerning the materials or methods used in this study or the findings specified in this paper.

\section{Author Contributions}

Conception and design: all authors. Acquisition of data: all authors. Analysis and interpretation of data: all authors. Drafting the article: all authors. Critically revising the article: all authors. Reviewed submitted version of manuscript: all authors. Approved the final version of the manuscript on behalf of all authors: Harris. Study supervision: Dyson, Elliot, Peterson, Ulbricht, Casey.

\section{Correspondence}

Lauren Harris: Imperial College Healthcare NHS Trust, Charing Cross Hospital, London, United Kingdom. lauren.harris7@nhs. net. 